\title{
Impact of phenolic-rich olive leaf extract on blood pressure, plasma lipids and inflammatory markers: a randomised controlled trial
}

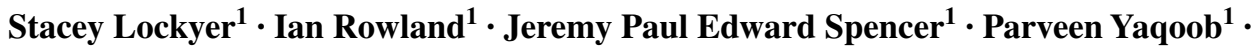 \\ Welma Stonehouse ${ }^{2,3}$
}

Received: 12 September 2015 / Accepted: 16 January 2016 / Published online: 7 March 2016

(C) The Author(s) 2016. This article is published with open access at Springerlink.com

\begin{abstract}
Purpose Dietary polyphenols have been demonstrated to favourably modify a number of cardiovascular risk markers such as blood pressure (BP), endothelial function and plasma lipids. We conducted a randomised, double-blind, controlled, crossover trial to investigate the effects of a phenolic-rich olive leaf extract (OLE) on BP and a number of associated vascular and metabolic measures.

Methods A total of 60 pre-hypertensive [systolic blood pressure (SBP): 121-140 $\mathrm{mmHg}$; diastolic blood pressure (DBP): $81-90 \mathrm{mmHg}$ ] males [mean age $45( \pm \mathrm{SD}$ 12.7 years, BMI $\left.26.7( \pm 3.21) \mathrm{kg} / \mathrm{m}^{2}\right]$ consumed either OLE (136 mg oleuropein; $6 \mathrm{mg}$ hydroxytyrosol) or a polyphenol-free control daily for 6 weeks before switching to the alternate arm after a 4-week washout.

Results Daytime [ $-3.95( \pm$ SD 11.48) $\mathrm{mmHg}, p=0.027]$ and 24-h SBP $[-3.33( \pm$ SD 10.81 $) \mathrm{mmHg}, p=0.045]$ and daytime and 24-h DBP $[-3.00( \pm$ SD 8.54$) \mathrm{mmHg}$, $p=0.025 ;-2.42( \pm$ SD 7.61) $\mathrm{mmHg}, p=0.039$ ] were all significantly lower following OLE intake, relative to the control.
\end{abstract}

Electronic supplementary material The online version of this article (doi:10.1007/s00394-016-1188-y) contains supplementary material, which is available to authorized users.

Jeremy Paul Edward Spencer

j.p.e.spencer@ reading.ac.uk

1 Hugh Sinclair Unit of Human Nutrition, Department of Food and Nutritional Sciences, University of Reading, Reading, Berkshire RG6 6AP, UK

2 School of Food and Nutrition, College of Health, Massey University, Auckland, New Zealand

3 Food and Nutrition Flagship, Commonwealth Scientific Industrial Research Organisation (CSIRO), Adelaide, Australia
Reductions in plasma total cholesterol $[-0.32( \pm$ SD 0.70$)$ $\mathrm{mmol} / \mathrm{L}, p=0.002]$, LDL cholesterol $[-0.19( \pm$ SD 0.56$)$ $\mathrm{mmol} / \mathrm{L}, p=0.017]$ and triglycerides $[-0.18( \pm$ SD 0.48$)$, $p=0.008]$ were also induced by OLE compared to control, whilst a reduction in interleukin-8 $[-0.63( \pm$ SD 1.13$) \mathrm{pg} / \mathrm{ml}$; $p=0.026]$ was also detected. Other markers of inflammation, vascular function and glucose metabolism were not affected.

Conclusion Our data support previous research, suggesting that OLE intake engenders hypotensive and lipid-lowering effects in vivo.

Keywords Olive leaf · Polyphenols $\cdot$ Cardiovascular disease $\cdot$ Blood pressure $\cdot$ Plasma lipids $\cdot$ Oleuropein

\section{Introduction}

Consumption of the so-called Mediterranean diet has been associated with a decreased risk of chronic diseases, in particular cardiovascular disease (CVD), when compared to other dietary regimes $[1,2]$. These effects may be attributed, in part, to the olive oil (OO) component of the diet [3]. Research comparing refined $\mathrm{OO}$ to extra virgin $\mathrm{OO}$ (EVOO) has highlighted the biological activity of the (poly)phenol components contained within the water-soluble fraction of EVOO [4, 5]. In addition to the fruit (from which $\mathrm{OO}$ is derived), the leaves of the olive plant (Olea europaea) also contain phenolic compounds at a much higher concentration than those of the olive fruit and oil (1450 mg total phenolics $/ 100 \mathrm{~g}$ fresh leaf [6] vs. $110 \mathrm{mg} / 100 \mathrm{~g}$ fruit [7] and $23 \mathrm{mg} / 100 \mathrm{ml}$ EVOO [8]). The most abundant phenolic compounds present in the leaves are verbascoside, apigenin7-glucoside, luteolin-7-glucoside, hydroxytyrosol (HT), tyrosol and the secoiridoid oleuropein, with secoiridoids being uniquely present in plants of the Oleaceae family [9]. 
Data emanating from a number of studies suggest that olive leaf extract (OLE) may influence CVD risk via its potential to induce anti-atherosclerotic, hypotensive, antioxidant, antiinflammatory and hypocholesterolaemic effects (for review see [10]). The majority of these have been animal studies with limited data relating to effects in humans; however, humanderived data have begun to appear in the literature. OLE has been reported to lower systolic blood pressure (SBP) and diastolic blood pressure (DBP) from baseline in both hypertensive and pre-hypertensive individuals [11-13] and to improve plasma lipid profiles in both normo-lipidaemic and hypercholesterolaemic subjects [11, 13-15]. OLE has also been found to induce acute reductions in arterial stiffness compared to a control by our research group [16], which agrees with data suggesting that $\mathrm{OO}$ significantly improves vascular function [17-19] and blood pressure [20] and these improvements are specifically associated with phenolic-rich rather than phenolicpoor OO [21]. In contrast, however, other studies have demonstrated that OLE supplementation has no effect on plasma lipids [12, 22], ambulatory blood pressure (ABP), cytokines or carotid intima-media thickness [22].

In order to better understand the impact of OLE intake, and to address the inconsistent existing data, the current randomised, controlled, double-blind, crossover intervention trial was designed to examine the effect of OLE on 24-h ambulatory blood pressure (BP) and a range of related vascular, lipid and inflammatory markers in 60 pre-hypertensive male volunteers.

\section{Methods}

\section{Subjects and screening}

A chronic human study was performed at the School of Food and Nutrition, Massey University, Auckland, New Zealand, from May-September 2013. The primary outcome measure was BP. Secondary outcome measures were vascular function, arterial stiffness, plasma lipids, glucose, insulin, fructosamine, oxidised LDL, C-reactive protein (CRP), adiponectin, cell adhesion molecules and cytokines.

\section{Power calculation}

A mean reduction of $5 \mathrm{mmHg}$ in $\mathrm{SBP}$ was chosen as a clinically significant end point, since at population level this has been estimated to relate to a $20 \%$ reduction in CVD morbidity and mortality [23]. To observe such a reduction using a crossover trial design with a standard deviation of 12.5 $\mathrm{mmHg}$ in a normal population would require 50 subjects to be longitudinally studied with $90 \%$ power and a significance value of 0.05 . Eleven extra subjects were enrolled to allow for dropouts.
Volunteers were recruited for the study through advertisements placed in local newspapers in the Auckland area and via flyers and posters on the Massey University campus as well as in shops and community buildings in the surrounding area. Email advertisements were sent to Massey University students and staff and those belonging to the IFNHH nutrition unit volunteer database. Individuals who responded to advertisements were asked to complete a health and lifestyle questionnaire online or by telephone. Those who fitted the inclusion criteria were invited to the clinical unit for assessment of further inclusion/exclusion criteria. Suitable subjects were pre-hypertensive, non-smoking males, free from chronic disease, including cardiovascular disease, diabetes, cancer, inflammatory or digestive disorders. Asthmatics and those consuming more than $21 \mathrm{U} /$ week of alcohol were excluded. Subjects were not taking anti-hypertensives, statins or other medication or dietary supplements that may affect BP, lipids or blood clotting, including fish oil. Pre-hypertensive subjects were identified as those presenting with average SBP in the range 121-140 $\mathrm{mmHg}$ and/or average DBP in the range $81-90 \mathrm{mmHg}$ at screening. Individuals with BP outside of these ranges were excluded. Subjects with food allergies or intolerances and those on a weight-reducing or restrictive diet (including vegetarian and vegan) were also excluded. Subjects arrived for screening fasted, and height and weight were measured using a stadiometer and Tanita weighing scales to calculate BMI. BP was measured after 5-min rest, seated and with the subject's left arm resting on a table, using an Omron digital BP monitor (HEM-907). Three readings were taken $60 \mathrm{~s}$ apart and averaged. Subjects were not permitted to talk during measurements. Mid-upper arm circumference (MUAC) was verified by tape measure in order to select the correct-sized BP cuff. A total of 61 suitable subjects were identified and accepted onto the trial.

\section{Randomisation and blinding}

Order of treatment allocation was done using the website randomization.com using a random block design. Products were labelled by an external individual using four-digit random number codes in identical bottles made from opaque plastic. The treatment codes were kept offsite and not released until statistical analysis was complete. Therefore, allocation concealment was achieved and both researchers and subjects were blinded to which product was being consumed at which time.

\section{Study design}

The study was a double-blind, randomised, controlled, crossover trial (Australia New Zealand Clinical Trials Registry number: ACTRN12613000180718, Clinicaltrials. gov ID: NCT01796561, see Fig. 1 for study design). This study was conducted according to the guidelines laid down 


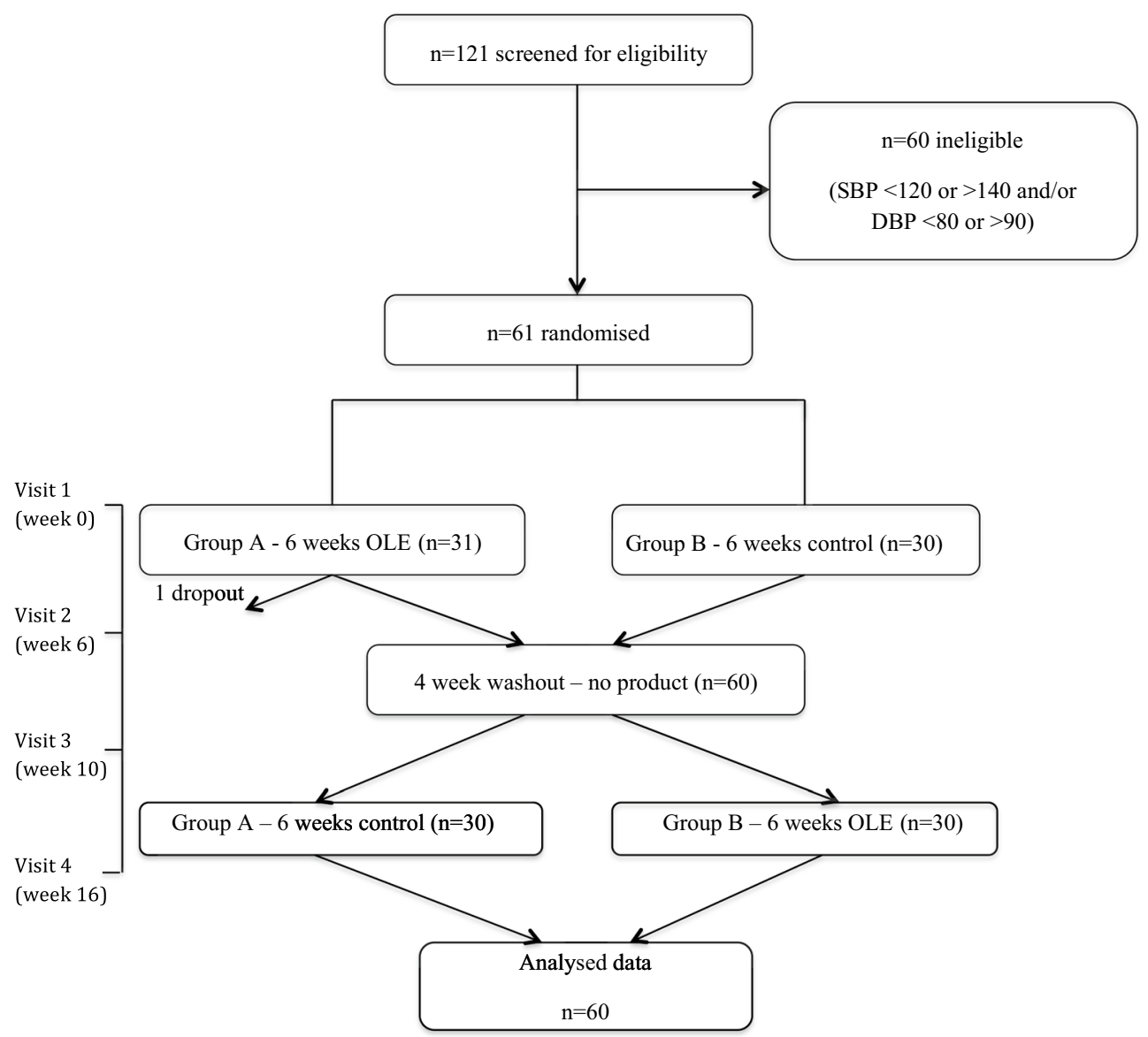

Fig. 1 Study flow

in the Declaration of Helsinki, and all procedures involving human subjects were approved by the University of Reading Research Ethics Committee (UREC 13/02). Written informed consent was obtained from all subjects. Sixtyone subjects aged 24-72 years consumed liquid OLE supplement or a control in a random order twice per day for 6 weeks, separated by a 4-week wash out period, during which no product was consumed. Six weeks was chosen as, in relation to health claims for food products, the European Food Safety Authority states that 'scientific evidence for the substantiation of health claims on the maintenance of normal blood pressure can be obtained from human intervention studies showing a short-term (e.g. 3-4 weeks) reduction in systolic blood pressure, or a reduction in diastolic blood pressure' [24]. Subjects avoided plant sterol-/stanolenriched spreads and all olive-containing products (olives, olive oil, olive margarine, tapenade) for the duration of the study (16 weeks). Clinical visits took place at weeks $0,6,10$ and 16 (before and after consuming each study product, four visits in total). Subjects refrained from consuming alcohol and taking part in strenuous exercise the day before study visits. The evening before study visits subjects consumed a standard low-fat meal of low phenolic content that was provided to participants (Weight Watchers macaroni cheese).

\section{Intervention}

The study product, 'Olive leaf extract, extra strength', is a commercially available, concentrated OLE liquid product manufactured by Comvita, Limited (Paengaroa, Te Puke, New Zealand) and comprises vegetable glycerine and water in a 50:50 ratio plus olive leaf extract. The commercial product is standardised to contain between 6.6 and $7.9 \mathrm{mg}$ oleuropein $/ \mathrm{ml}$; the batch used in this study contained $6.81 \mathrm{mg}$ oleuropein $/ \mathrm{ml}$ and $0.32 \mathrm{mg} \mathrm{HT} / \mathrm{ml}$, providing $136.2 \mathrm{mg}$ oleuropein and $6.4 \mathrm{mg}$ HT per day. The full phenolic profile can be found in Table 1 .

Subjects were instructed to consume $10 \mathrm{ml}$, twice per day, with food ( $20 \mathrm{ml}$ per day in total) and were supplied with measuring cups and spoons. The control product comprised vegetable glycerine and water in a 50:50 ratio plus commercially available food colourings and flavourings in safety-approved quantities in order to match OLE as closely as possible on appearance, taste, texture and aroma. 
Table 1 Phenolic composition of study product. Analysis performed via UPLC by product manufacturer (Comvita, Limited)

\begin{tabular}{ll}
\hline Phenolic compound & $\mathrm{mg} / \mathrm{ml}$ \\
\hline Oleuropein & 6.81 \\
Oleoside & 0.73 \\
Hydroxytyrosol & 0.32 \\
Luteolin-7-O-glucoside & 0.17 \\
Tyrosol & 0.12 \\
Verbascoside & 0.09 \\
Apigenin-7- $O$-glucoside & 0.07 \\
Rutin & 0.02 \\
Vanillic acid & 0.01 \\
Vanillin & 0.01 \\
Luteolin & 0.01 \\
\hline
\end{tabular}

\section{Clinical visits}

Subjects arrived for all clinical visits in a 12-h fasted state. Temperature was measured with an inner ear thermometer (Braun Thermoscan 6014) to check for the presence of acute infections. Subjects rested supine for $10 \mathrm{~min}$ before vascular function measurements began. Measurements were taken in a quiet room by a single trained operator. The SphygmoCor (AtCor Medical, Sydney) was used to measure pulse wave velocity (PWV). Pulse wave velocity has been validated and shown to be an independent predictor of cardiovascular mortality and morbidity [25]. The velocity at which pulse waves travel along arteries is dependent on the elasticity of the artery walls. PWV measures the amount of time taken for pressure waves to travel over a known distance and is calculated as the distance between the two positions of the pulse transducer divided by the time delay measured between pressure upstroke at each site. Here, PWV was recorded between carotid and femoral artery sites. The pressure wave was recorded directly by means of a high-fidelity applanation tonometer which is a force recorder. The less elastic, or more stiff, the artery walls, the faster the velocity and the higher the PWV value [26]. Pulse wave analysis (PWA) is a non-invasive method which measures augmentation index (AIx), a manifestation of arterial stiffness. The method is sensitive to acute effects such as the ingestion of red wine [27] and black and green tea [28]. AIx is strongly correlated with PWV [29]. PWA was performed using the SphygmoCor, whereby a hand-held tonometry probe was used to flatten the subject's radial artery. The SphygmoCor takes a 10-s snapshot of the arterial pressure wave and derives the ascending aortic pressure wave, measuring AIx. AIx indicates the augmentation of the incident pulse wave due to the reflection and is found by taking the difference between the first and second derived aortic systolic peaks as a percentage of pulse pressure. AIx has been found to be influenced by heart rate [30] and so an index normalised for a heart rate of $75 \mathrm{bpm}$ (AIx@75) was used here. Body composition was assessed via bioelectrical impedance using an InBody 230 analyser. Blood samples obtained via single venepuncture were collected into heparin and EDTA vacutainers (BD).

\section{Compliance measures}

Subjects were asked to return all remaining bottles of study product at the end of each intervention period. Remaining liquid supplement was weighed and recorded. Subjects were asked to complete weekly online questionnaires and supplied with daily tick sheets.

\section{Blood pressure}

Twenty-four-hour $\mathrm{ABP}$ was assessed at weeks $0,6,10$ and 16 using automated monitors (Model TM-2430, Scan Med, A\&D Medical, UK). Devices were programmed to measure BP every 30 min between the hours of 0700 and 2200 and every $60 \mathrm{~min}$ between the hours of 2200 and 0700 with the cuff located on the upper left arm. In order to collect accurate data for a 24-h period, subjects were asked to wear the monitors for a duration of $25 \mathrm{~h}$, and the first two readings following fitting of the device were excluded to allow for subjects to adjust to the presence of the machine. Subjects were asked to refrain from strenuous exercise whilst wearing the monitor and to keep the device on for the entire 25-h period, apart from when showering and dressing, which was to be done between measurements. Subjects were instructed to use the BP monitors on a similar type of day to standardise for activity level, in particular to account for differences that may arise due to a work or non-work day. Subjects completed an activity diary and recorded sleep and wake times, which were used to classify data into 'night' and 'day' periods. Here, data collected within night and day periods were averaged, and an average of the whole $24-\mathrm{h}$ period was also calculated.

\section{Biochemical measures}

Blood collected in EDTA and heparin vacutainers was centrifuged at $1550 \times g$ for $15 \mathrm{~min}$ to separate plasma. Plasma was stored in low-binding Eppendorf tubes (Axygen, Tewksbury MA, USA) at $-80{ }^{\circ} \mathrm{C}$ until analysis. Total cholesterol (TC), HDL cholesterol (HDL-C), triglycerides (TAG), glucose and insulin were measured at North Shore Hospital, Auckland, in a Dimension Vista 1500 Intelligent Lab System. LDL cholesterol (LDL-C) was calculated using the Friedewald formula: [(LDL-C) $=(\mathrm{TC})-(\mathrm{HDL}-$ C) - (TAG)/2.2]. QUICKI was calculated using the formula: $1 /(\log$ insulin $+\log$ glucose). HOMA-IR was calculated 
using the formula: (glucose $\times$ insulin)/22.5. Fructosamine was measured using a colorimetric assay (Roche Cobas, Indianapolis, USA). Vascular cell adhesion molecule-1 (VCAM-1), intercellular adhesion molecule-1 (ICAM-1), E-selectin, P-selectin, CRP and adiponectin were analysed using multiplex Luminex kits following standard instructions provided by the manufacturer (R\&D). IL- $6, \mathrm{TNF}-\alpha, \mathrm{IL}-1-\beta$, IL-10 and IL-8 were measured in a random subset of subjects (mean age $42.3 \pm 13.1$ years) using an ultrasensitive multiplex Luminex kit (R\&D). Oxidised LDL was measured in duplicate via an ELISA kit (Mercodia, Sweden). Plasma samples were analysed for nitrite and nitrate using chemiluminescence. Briefly, samples and standards containing nitrite and nitrate were first reduced to NO, which was then quantified using an NO analyser (NOA Eco Physics chemiluminescence detector, model 88 et). To determine total nitrite and nitrate concentrations, collectively termed 'NOx', samples were added to $0.1 \mathrm{~mol} / \mathrm{L}$ vanadium (III) chloride in $1 \mathrm{M}$ hydrochloric acid refluxing at $90{ }^{\circ} \mathrm{C}$. Nitrite concentrations were determined by addition of samples to $1.1 \%$ potassium iodide in glacial acetic acid under nitrogen at room temperature. Concentrations of nitrate were calculated by subtraction of nitrite from NOx values.

\section{Statistical analysis}

Statistical analysis was performed using SPSS statistics software version 21 (IBM) for data in which a complete set of four values (one per clinical visit) was available for a subject per variable. Data were checked for normality using the Kolmogorov-Smirnov and Shapiro-Wilk tests. Order of treatment effects was assessed using 2-way analysis of variance. Where there were no group $\times$ treatment interactions present, whole group data were analysed. Significant group $\times$ treatment effects were indicated for fructosamine and IL-6 and so only data from visits 1 and 2 were used for these variables. Data were grouped by treatment, and difference values were calculated by subtracting the baseline values from the end of treatment period values. Difference values from the two treatments were compared to each other using a paired Student's $t$ test. $p$ values $<0.05$ were deemed statistically significant.

\section{Results}

\section{Compliance}

One subject withdrew from the study after the first clinical visit due to relocation. There were no other dropouts, and 60 subjects completed the study. Weighing of the remaining liquid OLE product revealed a compliance rate of $70.19 \%$ $( \pm \mathrm{SD} 17.72)$ to OLE and $74.54 \%( \pm \mathrm{SD} 18.28)$ to the
Table 2 Baseline characteristics of the subjects

\begin{tabular}{ll}
\hline Variable & Mean $(\mathrm{SD})$ \\
\hline Age $($ years $)$ & $45.3( \pm 12.7)$ \\
BMI $\left(\mathrm{kg} / \mathrm{m}^{2}\right)$ & $27.0( \pm 3.4)$ \\
$\%$ body fat & $22.5( \pm 6.6)$ \\
Total cholesterol (mmol/L) & $5.0( \pm 1.0)$ \\
LDL cholesterol $(\mathrm{mmol} / \mathrm{L})$ & $3.1( \pm 0.9)$ \\
HDL cholesterol $(\mathrm{mmol} / \mathrm{L})$ & $1.3( \pm 0.4)$ \\
Triglycerides $(\mathrm{mmol} / \mathrm{L})$ & $1.4( \pm 0.9)$ \\
TC/HDL cholesterol ratio & $4.3( \pm 1.7)$ \\
Glucose $(\mathrm{mmol} / \mathrm{L})$ & $5.2( \pm 0.4)$ \\
Insulin $(\mathrm{mU} / \mathrm{L})$ & $8.9( \pm 5.8)$ \\
24-h SBP/DBP $(\mathrm{mmHg})$ & $135( \pm 11) / 81( \pm 8)$ \\
Daytime SBP/DBP $(\mathrm{mmHg})$ & $139( \pm 12) / 83( \pm 9)$ \\
Night time SBP/DBP $(\mathrm{mmHg})$ & $116( \pm 10) / 68( \pm 8)$ \\
\hline
\end{tabular}

$B M I$ body mass index, $L D L$ low-density lipoprotein, $H D L$ high-density lipoprotein, $T C$ total cholesterol, $S B P$ systolic blood pressure, $D B P$ diastolic blood pressure

control. One subject experienced acne, and four subjects experienced mild stomach upset during the course of intervention, but these symptoms were also experienced by subjects on the control and did not result in subject withdrawal from the study.

\section{Baseline characteristics of the subjects}

All subjects were free from diagnosed chronic disease with a mean daytime $\mathrm{BP}$ of $139 / 83 \mathrm{mmHg}$ (Table 2), classifying them as prehypertensive [31]. Average BMI was $26.7 \mathrm{~kg} /$ $\mathrm{m}^{2}$, although subjects ranged from 20.4 to $37.4 \mathrm{~kg} / \mathrm{m}^{2}$ (healthy to obese). Subjects had total cholesterol, LDL-C and TC/HDL-C levels above that considered physiologically normal $(5 \mathrm{mmol} / \mathrm{L}, 3.1 \mathrm{mmol} / \mathrm{L}$ and 4.3 vs. guideline values of $<4 \mathrm{mmol} / \mathrm{L},<2 \mathrm{mmol} / \mathrm{L}$ and $<4$, respectively [32]) (Table 2). Triglyceride and HDL-C concentrations were within the normal range $(1.4$ and $1.3 \mathrm{mmol} / \mathrm{L}$ vs. guideline values of $<1.7$ and $\geq 1 \mathrm{mmol} / \mathrm{L})$.

\section{Blood pressure and vascular function}

Twenty-four-hour SBP, 24-h DBP and daytime SBP and DBP were all significantly reduced following intake of the OLE relative to control due to a decrease in BP after OLE consumption and an increase in BP after the control (Table 3). There were no significant differences between the effects of the two treatments on night time BP (Table 3). No significant impact of OLE on PWV was detected, although there was a tendency for OLE to attenuate an increase in PWA-AI@HR75 after consumption of the control $(p=0.071)$ (Table 4). 


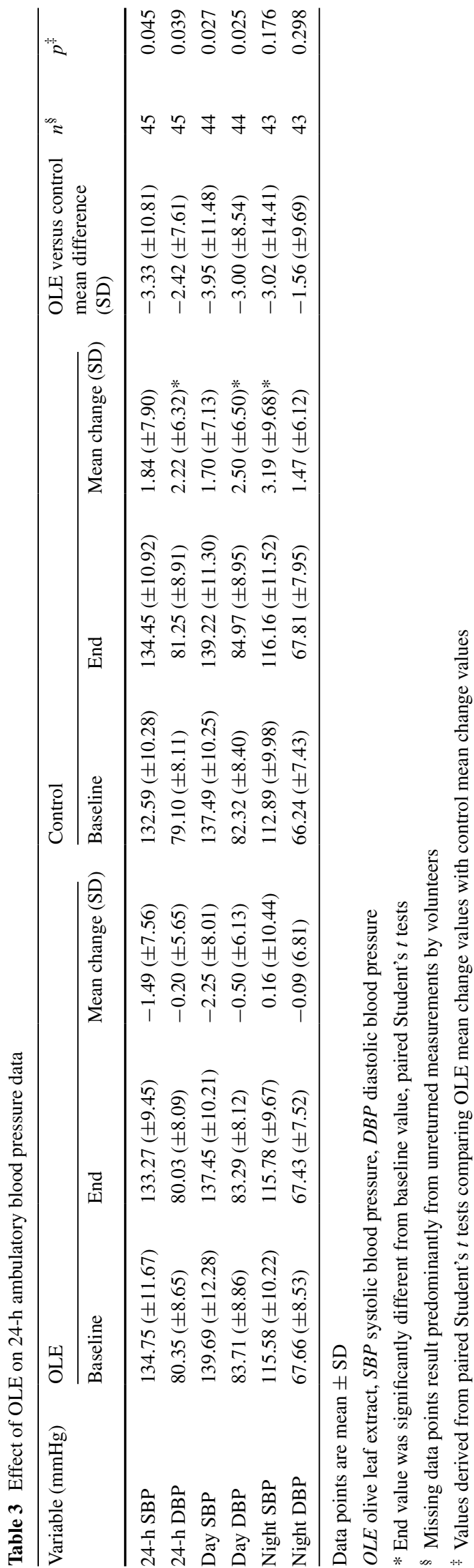

\section{Biochemical analysis and body composition}

OLE intake significantly reduced plasma TC, LDL-C and TAG from baseline. Overall reductions relative to the control were $0.32,0.19$ and $0.18 \mathrm{mmol} / \mathrm{L}$, respectively (Table 5). HDL-C significantly decreased from baseline following consumption of OLE; however, there were no significant effects on HDL-C or the LDL-C/HDL-C ratio compared to the control. There was a near-significant decrease in total cholesterol/HDL-C ratio following OLE consumption ( $p=0.055$ ) compared to the control (Table 5). There were no effects of OLE intake on fasting glucose, insulin, fructosamine or calculated HOMA-IR or QUICKI indices (Table 6). Similarly there was no effect on oxidised LDL, CRP, adiponectin, ICAM-1, VCAM-1, P-selectin, E-selectin, IL-6, IL-10, IL-1 $\beta$ or TNF- $\alpha$ (Table 7). However, OLE significantly reduced plasma IL-8 compared to the control $(p<0.05)$ (Table 7). There was no significant difference in plasma nitrite between the two groups (olive leaf change from baseline: $71.6 \mathrm{nM} \pm 801, n=38$; control change from baseline: $114 \mathrm{nM} \pm 732, n=38$ ). There was no impact of either treatment on body composition (see Supplementary Material Table S1).

\section{Discussion}

Previous studies have indicated potential blood pressure and lipid-lowering effects of OLE in humans, but results have thus far lacked consistency, perhaps due to differences in phenolic dose, duration and study design. Here, we provide data demonstrating that OLE has the potential to significantly reduce 24-h and daytime SBP and 24-h and daytime DBP relative to control. The magnitude of BP changes observed here (SBP by 3.33 and $3.95 \mathrm{mmHg}$ and DBP by 2.42 and $3.00 \mathrm{mmHg}(24 \mathrm{~h}$ and daytime values, respectively)) can be considered physiologically significant. Data from observational studies suggest that $2 \mathrm{~mm} \mathrm{Hg}$ reductions in SBP and DBP are associated with $6 \%$ and 7 $\%$ reductions in CHD risk and $10 \%$ and $15 \%$ reductions in stroke and heart attack respectively [33, 34]. Extrapolating from this would suggest that regular OLE intake may be associated with a 9-14\% reduction in CHD risk and a 20-22.5\% reduction in risk of stroke and heart attack.

It has been postulated that oleuropein is the key hypotensive component of OLE due to L-type $\mathrm{Ca}^{2+}$ channel antagonistic effects $[35,36]$. In addition, verbascoside has been demonstrated to inhibit angiotensin-converting enzyme in vitro [37] as has oleacein [38]. With respect to oleuropein, our intervention provided $136 \mathrm{mg} /$ day, compared to $200 \mathrm{mg} /$ day used in two previous studies; which resulted in mean reductions in systolic and diastolic blood pressure of 13 and $5 \mathrm{mmHg}$, respectively, in pre-hypertensive MZ twins [11] 
Table 4 Effect of OLE on vascular function measures

\begin{tabular}{|c|c|c|c|c|c|c|c|c|c|}
\hline \multirow[t]{2}{*}{ Variable } & \multicolumn{3}{|l|}{ OLE } & \multicolumn{3}{|l|}{ Control } & \multirow{2}{*}{$\begin{array}{l}\text { OLE versus } \\
\text { control mean } \\
\text { difference (SD) }\end{array}$} & \multirow[t]{2}{*}{$n$} & \multirow[t]{2}{*}{$p^{\ddagger}$} \\
\hline & Baseline & End & $\begin{array}{l}\text { Mean change } \\
\text { (SD) }\end{array}$ & Baseline & End & $\begin{array}{l}\text { Mean change } \\
\text { (SD) }\end{array}$ & & & \\
\hline PWV (m/s) & $9.35( \pm 1.94)$ & $9.06( \pm 1.54)$ & $-0.29( \pm 1.41)$ & $9.45( \pm 1.71)$ & $8.97( \pm 1.86)$ & $-0.48( \pm 1.58)^{*}$ & $0.19( \pm 1.91)$ & 54 & 0.461 \\
\hline $\begin{array}{c}\text { PWA-AI@ } \\
\text { HR75 (\%) }\end{array}$ & $10.19( \pm 12.67)$ & $11.37( \pm 12.28)$ & $1.19( \pm 5.92)$ & $9.54( \pm 11.96)$ & $12.94( \pm 10.62)$ & $3.41( \pm 3.41)^{*}$ & $-2.22( \pm 8.86)$ & 54 & 0.071 \\
\hline
\end{tabular}

Data points are mean $\pm \mathrm{SD}$

$O L E$ olive leaf extract, $P W V$ pulse wave velocity, PWA-AI@HR75 pulse wave analysis-derived augmentation index corrected to a heart rate of $75 \mathrm{bpm}$

* End value was significantly different from baseline value, paired Student's $t$ tests

$¥$ Values derived from paired Student's $t$ tests comparing OLE mean change values with control mean change values

Table 5 Effect of OLE on fasting plasma lipids

\begin{tabular}{|c|c|c|c|c|c|c|c|c|c|}
\hline \multirow[t]{2}{*}{ Variable } & \multicolumn{3}{|l|}{ OLE } & \multicolumn{3}{|l|}{ Control } & \multirow{2}{*}{$\begin{array}{l}\text { OLE versus } \\
\text { control mean } \\
\text { difference (SD) }\end{array}$} & \multirow[t]{2}{*}{$n$} & \multirow[t]{2}{*}{$p^{\ddagger}$} \\
\hline & Baseline & End & $\begin{array}{l}\text { Mean change } \\
\text { (SD) }\end{array}$ & Baseline & End & $\begin{array}{l}\text { Mean change } \\
\text { (SD) }\end{array}$ & & & \\
\hline $\begin{array}{l}\text { Total cholesterol } \\
(\mathrm{mmol} / \mathrm{L})\end{array}$ & $5.11( \pm 0.99)$ & $4.78( \pm 0.99)$ & $-0.33( \pm 0.47)^{*}$ & $5.02( \pm 1.02)$ & $5.00( \pm 0.97)$ & $-0.01( \pm 0.44)$ & $-0.32( \pm 0.70)$ & 52 & 0.002 \\
\hline $\begin{array}{l}\text { LDL-C } \\
\qquad(\mathrm{mmol} / \mathrm{L})\end{array}$ & $3.14( \pm 0.88)$ & $2.94( \pm 0.87)$ & $-0.20( \pm 0.41)^{*}$ & $3.09( \pm 0.90)$ & $3.08( \pm 0.89)$ & $-0.01( \pm 0.37)$ & $-0.19( \pm 0.56)$ & 52 & 0.017 \\
\hline $\begin{array}{l}\text { HDL-C } \\
\quad(\mathrm{mmol} / \mathrm{L})\end{array}$ & $1.29( \pm 0.40)$ & $1.24( \pm 0.34)$ & $-0.05( \pm 0.18)^{*}$ & $1.30( \pm 0.38)$ & $1.29( \pm 0.38)$ & $-0.007( \pm 0.17)$ & $-0.04( \pm 0.24)$ & 52 & 0.202 \\
\hline TAG (mmol/L) & $1.48( \pm 0.87)$ & $1.30( \pm 0.77)$ & $-0.18( \pm 0.46)^{*}$ & $1.39( \pm 0.88)$ & $1.40( \pm 0.84)$ & $0.004( \pm 0.51)$ & $-0.18( \pm 0.48)$ & 52 & 0.008 \\
\hline $\begin{array}{l}\text { LDL-C/HDL-C } \\
\text { ratio }\end{array}$ & $2.68( \pm 1.18)$ & $2.58( \pm 1.12)$ & $-0.09( \pm 0.42)$ & $2.61( \pm 1.16)$ & $2.63( \pm 1.16)$ & $0.02( \pm 0.39)$ & $-0.12( \pm 0.54)$ & 52 & 0.125 \\
\hline TC/HDL-C ratio & $4.32( \pm 1.72)$ & $4.16( \pm 1.63)$ & $-0.16(0.54)^{*}$ & $4.22( \pm 1.73)$ & $4.24( \pm 1.74)$ & $0.03( \pm 0.44)$ & $-0.19( \pm 0.70)$ & 52 & 0.055 \\
\hline
\end{tabular}

Data points are mean $\pm \mathrm{SD}$

$O L E$ olive leaf extract, $L D L-C$ low-density lipoprotein cholesterol, $H D L-C$ high-density lipoprotein cholesterol, $T A G$ triglycerides, $T C$ total cholesterol

* End value was significantly different from baseline value, paired Student's $t$ tests

$\ddagger$ Values derived from paired student’s $t$ tests comparing OLE mean change values with control mean change values

Table 6 Effect of OLE on measures of glucose metabolism

\begin{tabular}{|c|c|c|c|c|c|c|c|c|c|}
\hline \multirow[t]{2}{*}{ Variable } & \multicolumn{3}{|l|}{ OLE } & \multicolumn{3}{|l|}{ Control } & \multirow{2}{*}{$\begin{array}{l}\text { OLE versus } \\
\text { control mean } \\
\text { difference (SD) }\end{array}$} & \multirow[t]{2}{*}{$n$} & \multirow[t]{2}{*}{$p^{\ddagger}$} \\
\hline & Baseline & End & $\begin{array}{l}\text { Mean change } \\
\text { (SD) }\end{array}$ & Baseline & End & $\begin{array}{l}\text { Mean change } \\
\text { (SD) }\end{array}$ & & & \\
\hline $\begin{array}{l}\text { Glucose } \\
(\mathrm{mmol} / \mathrm{L})\end{array}$ & $5.32( \pm 0.44)$ & $5.27( \pm 0.54)$ & $-0.05( \pm 0.37)$ & $5.28( \pm 0.46)$ & $5.33( \pm 0.43)$ & $0.05( \pm 0.32)$ & $-0.10( \pm 0.52)$ & 52 & 0.163 \\
\hline Insulin (mU/L) & $9.46( \pm 6.1)$ & $8.86 \pm(5.25)$ & $-0.60( \pm 4.50)$ & $9.27( \pm 5.73)$ & $9.97( \pm 7.49)$ & $0.70( \pm 5.15)$ & $-1.30( \pm 7.19)$ & 52 & 0.197 \\
\hline HOMA-IR & $2.28( \pm 1.57)$ & $2.13( \pm 1.45)$ & $-0.15( \pm 1.18)$ & $2.25(1.64)$ & $2.42(1.96)$ & $0.17( \pm 1.21)$ & $-0.32( \pm 1.80)$ & 52 & 0.483 \\
\hline QUICKI & $0.63( \pm 0.10)$ & $0.64( \pm 0.09)$ & $0.01( \pm 0.07)$ & $0.63( \pm 0.11)$ & $0.63( \pm 0.12)$ & $-0.002( \pm 0.07)$ & $0.01( \pm 0.10)$ & 52 & 0.482 \\
\hline $\begin{array}{l}\text { Fructosamine }^{\S} \\
(\mu \mathrm{mol} / \mathrm{L})\end{array}$ & $\begin{array}{l}230.41 \\
( \pm 18.04)\end{array}$ & $\begin{array}{l}221.24 \\
( \pm 15.94)\end{array}$ & $-9.17( \pm 13.19)$ & $\begin{array}{l}229.29 \\
( \pm 14.30)\end{array}$ & $\begin{array}{l}222.48 \\
( \pm 15.17)\end{array}$ & $-6.81( \pm 14.82)$ & -2.36 & 29,31 & 0.517 \\
\hline
\end{tabular}

$O L E$ olive leaf extract, HOMA-IR homoeostasis model assessment-estimated insulin resistance, $Q U I C K I$ quantitative insulin sensitivity check index

\# Values derived from paired Student's $t$ tests comparing OLE mean change values with control mean change values

$\S$ Significant treatment $\times$ sequence interactions were shown for this variable; therefore, only data derived from the first intervention period (week 0-week 6) are reported 


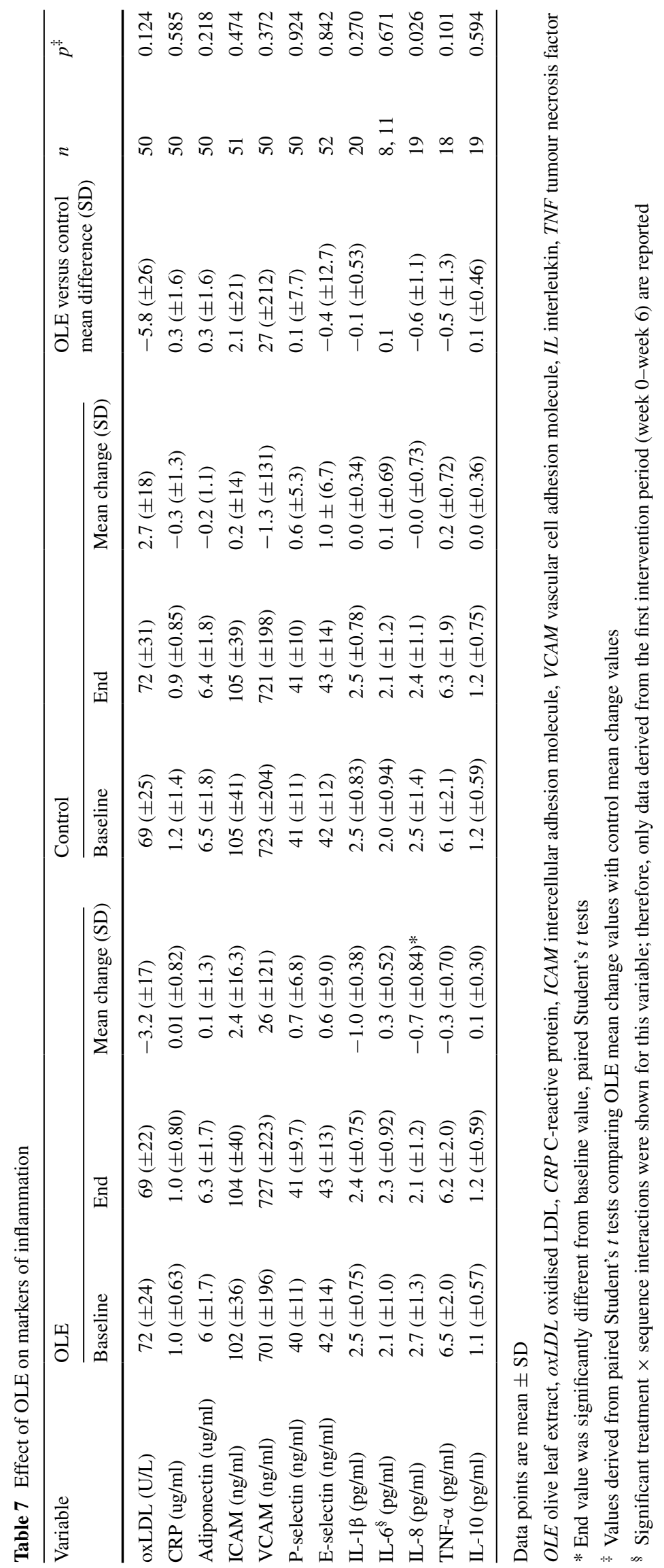


and 12 and $5 \mathrm{mmHg}$, respectively, in hypertensive patients [13] a magnitude of effect similar to that of Captopril, a common anti-hypertensive drug [13]. In a further study, a dose of $51 \mathrm{mg}$ oleuropein/day induced no significant reductions in BP [22] although this study tested OLE capsules, which may be less bioavailable than the liquid used in the current study [39]. Assuming linearity between dose and BP reductions, our prescribed dose would be expected to yield a reduction of approximately $8 \mathrm{mmHg}$, higher than that measured in our study. However, as our compliance rate was $70.19 \%$ with respect to OLE consumption, daily oleuropein intake can be estimated to be lower at around $95 \mathrm{mg}$ oleuropein per day. Furthermore, we employed 24-h ambulatory BP measures in our study, which arguably provide more robust information on BP compared to the single measures used in the aforementioned studies [40]. Studies examining the effects of $\mathrm{OO}$ phenolics and their metabolites suggest that these may influence NO production in vivo [41], or scavenge ROS in the vasculature [42], following their appearance in the circulation. Whilst previous studies have linked the phenolic content of $\mathrm{OO}$ with increases in nitric oxide and ultimately clinical outcomes [20, 43], we observed no significant impact on circulating nitrites. It is possible that nitrite contamination from the use of samples collected in EDTA tubes lead to the high standard deviation of this data and masked any changes that occurred. Additionally, it is noteworthy that the product used here has not been completely characterised meaning that other bioactives aside from polyphenols, such as minerals, squalene and, triterpenoids such as oleanolic, ursolic and maslinic acids [44], could have been responsible for the observed blood pressure effects, thus pointing towards a different mechanism of action besides NO. For example, African olive leaf cultivars which are triterpenoid-rich and polyphenol-poor have been reported to prevent hypertension and atherosclerosis and improve insulin resistance in Dahl salt-sensitive rats [45].

With arguably more pronounced effects than on BP, OLE intake was also associated with physiologically significant reductions in TC, LDL-C and TAG of 0.32, 0.19 and $0.18 \mathrm{mmol} / \mathrm{L}$, respectively, when compared to the control, with no detrimental effect on HDL-C. Considering previous trials conducted with statins, the TC and LDL-C reductions reported in the present study could equate to an overall CVD risk reduction of $4.2 \%$ [46] and $9.75 \%$ [47], respectively. Similarly, data from a meta-analysis of populationbased prospective cohort studies report that a $1 \mathrm{mmol} / \mathrm{L}$ increase in TAG results in a $32 \%$ CHD risk increase. On this basis, consumption of OLE at the dose provided in our study may promote a $5.76 \%$ CHD risk reduction [48]. Data regarding the effects of OLE on plasma lipids have been somewhat inconsistent. For example, in a study of 20 MZ twin pairs, a $200 \mathrm{mg} /$ day intake of oleuropein resulted in a $0.6 \mathrm{mmol} / \mathrm{L}$ decrease in $\mathrm{TC}$, a $0.4 \mathrm{mmol} / \mathrm{L}$ decrease in
LDL cholesterol and no change in TAG relative to healthy lifestyle advice alone after 8 weeks, whilst a $100 \mathrm{mg} /$ day dose had no significant effects on lipids [11], whereas a larger study $(n=148)$ found less efficacious changes of $-0.15 \mathrm{mmol} / \mathrm{L}$ in $\mathrm{TC},-0.10 \mathrm{mmol} / \mathrm{L}$ in $\mathrm{LDL}-\mathrm{C}$ and $-0.13 \mathrm{mmol} / \mathrm{L}$ in TAG [13]. A more recent study reported decreases of $0.68,0.90$ and $0.047 \mathrm{mmol} / \mathrm{L}$ in TC, LDL-C and TAG, respectively (with a non-significant increase in HDL-C), after 12 months consumption of a supplement containing $100 \mathrm{mg}$ oleuropein [15], providing some evidence of sustained and larger effects over longer periods of time. Individual differences in the absorption and metabolism of OLE phenolics could be responsible [39].

The mechanisms underlying the lipid-lowering effects of OLE are presently unknown. However, animal data suggest that the consumption of phenolic components of OLE appears to decrease the activities of key cholesterol-regulatory enzymes, 3-hydroxy- 3-methylglutaryl-CoA (HMG-CoA) reductase (the main target of statins) and acetyl-CoA cholesterol acyltransferase (ACAT), resulting in decreased cholesterol biosynthesis [49]. Additional animal data suggest that olive phenolics may impact on bile flow, increasing biliary cholesterol and bile acid concentrations, leading to their increased faecal excretion [50]. Interestingly, a recent paper reporting favourable modification of lipid profiles by OLE [15] also observed osteoblast stimulation and hypothesised that as osteoblasts and adipocytes derive from the same mesenchymal stem cells, this may explain the change in lipid profiles. Once again, there is evidence to suggest that non-phenolic components may contribute to lipidlowering effects [51].

Chronic OLE intake reduced plasma IL-8 concentration in a subgroup of the subjects $(n=19)$. Due to the high natural variability of cytokine production, greater power may be required for reliable and meaningful data [52]. When accounting for multiple comparisons of inflammatory markers, the result is no longer significant (a $p$ value $<0.004$ would be needed to be statistically significant [0.05/12 comparisons (12 inflammatory markers)]; however, the finding reflects our previous data, indicating that an acute dose of OLE decreases ex vivo production of LPSstimulated IL-8 (but not other cytokines) in whole blood cultures [16]. Anti-inflammatory effects of OLE are also indicated by its use in a patented haemorrhoid treatment [53], and from data demonstrating that OLE phenolics reduce inflammatory cytokines in animal [54] and ex vivo [55] studies [22]. IL-8 is associated with increased risk of future CVD incidences [56], perhaps through its ability to destabilise existing atherosclerotic plaques by down-regulation of tissue inhibitors of metalloproteinase expression [57]. However, cytokines lack the robustness of other CVD biomarkers such as blood pressure and plasma lipids, and it is difficult to attribute clinical importance to reductions in these markers [58]. 
The effect of OLE on glycaemic control was worthy of investigation as chronic OLE supplementation has been related to improvements in an oral glucose tolerance test and additionally $1 \mathrm{~g}$ olive leaf fed with $300 \mathrm{~g}$ white rice has been observed to significantly reduce blood glucose at 30 and $60 \mathrm{~min}$ in borderline diabetics [22, 59]. In both instances, these effects were thought to be mediated by the inhibitory action of OLE polyphenols on intestinal and/or salivary $\alpha$-amylases; however, it is also possible that OLE aglycones compete with glucose released from food in the gut for glucose receptors, resulting in less absorption. In the present study, there were no significant effects of OLE on fasting glucose, insulin, fructosamine, QUICKI or HOMA-IR indices. In line with this, a previous study has indicated no change in fasting glucose after 3-week VOO supplementation compared to refined OO [60].

\section{Conclusion}

The present study has strengthened the existing body of evidence that OLE has the potential to favourably modify blood pressure and plasma lipid profiles. The magnitude of the risk-lowering potential we describe could have significant impact at population level in countries with high prevalence of CVD. The impact of dietary factors towards CVD risk has informed the provision of a diet rich in fruit and vegetables in the primary prevention of hypertension and raised cholesterol [61, 62]. In the near future, there may be enough evidence for this advice to be extended to include phenolic-rich foods. Daily consumption of OLE can result in favourable improvements in several CVD risk factors which could result in a moderate but nonetheless significant reduction in risk, making it a useful addition to a healthy diet and lifestyle.

Acknowledgments S.L. would like to thank the following for their contributions to this work: Dr. Gunter Kuhnle and Professor AnneMarie Minihane for their comments on the manuscript, Dr. Jane Parker for helping in the development of the control liquid; Teresa Roberts, Kathleen Paris, Jamie de Seymour and Carmel Trubuhovich for aiding with the implementation of the human study, Sarah Philipsen, Tessa Anderson and Kathrin Nenz and Dr. Giulia Corona for assisting with sample processing and assay procedures and with special thanks to P.C. Tong for help and advice relating to all practical aspects of the project.

Financial support This work was funded by Comvita Limited and Callaghan Innovation who supported $50 \%$ of the funding as a Technology for Business Growth grant.

\section{Compliance with ethical standards}

Conflict of interest Fifty percentage of the funding for this study was provided by Comvita Limited, the manufacturers of the olive leaf extract. Comvita Limited had no part in the design, running of the study or data analysis.
Open Access This article is distributed under the terms of the Creative Commons Attribution 4.0 International License (http://creativecommons.org/licenses/by/4.0/), which permits unrestricted use, distribution, and reproduction in any medium, provided you give appropriate credit to the original author(s) and the source, provide a link to the Creative Commons license, and indicate if changes were made.

\section{References}

1. López-Miranda J, Pérez-Jiménez F, Ros E et al (2010) Olive oil and health: summary of the II international conference on olive oil and health consensus report, Jaén and Córdoba (Spain) 2008. Nutr Metab Cardiovasc Dis 20:284-294

2. Barzi F, Woodward M, Marfisi R et al (2003) Mediterranean diet and all-causes mortality after myocardial infarction: results from the GISSI-Prevenzione trial. Eur J Clin Nutr 57:604-611

3. Cicerale S, Lucas L, Keast R (2010) Biological activities of phenolic compounds present in virgin olive oil. Int J Mol Sci 11:458-479

4. Ramirez-Tortosa MC, Urbano G, López-Jurado M et al (1999) extra-virgin olive oil increases the resistance of LDL to oxidation more than refined olive oil in free-living men with peripheral vascular disease. J Nutr 129:2177-2183

5. Marrugat J, Covas M-I, Fitó M et al (2004) Effects of differing phenolic content in dietary olive oils on lipids and LDL oxidation. Eur J Nutr 43:140-147. doi:10.1007/s00394-004-0452-8

6. Silva S, Gomes L, Leitao F et al (2006) Phenolic compounds and antioxidant activity of Olea europaea L. fruits and leaves. Food Sci Technol Int 12:385-395

7. Kountouri AM, Mylona A, Kaliora AC et al (2007) Bioavailability of the phenolic compounds of the fruits (drupes) of Olea europaea (olives): impact on plasma antioxidant status in humans. Phytomedicine 14:659-667

8. Owen RW, Mier W, Giacosa A et al (2000) Phenolic compounds and squalene in olive oils: the concentration and antioxidant potential of total phenols, simple phenols, secoiridoids, lignansand squalene. Food Chem Toxicol 38:647-659. doi:10.1016/ S0278-6915(00)00061-2

9. Petkov V, Manolov P (1972) Pharmacological analysis of the iridoid oleuropein. Arzneim Forsch (Drug Res) 22:1476-1488

10. Lockyer S, Yaqoob P, Spencer J et al (2012) Olive leaf phenolics and cardiovascular risk reduction: physiological effects and mechanisms of action. Nutr Aging 1:125-140

11. Perrinjaquet-Moccetti T, Busjahn A, Schmidlin C et al (2008) Food supplementation with an olive (Olea europaea L.) leaf extract reduces blood pressure in borderline hypertensive monozygotic twins. Phytother Res 22:1239-1242. doi:10.1002/ ptr. 2455

12. Cherif N, Rahal M, Haouala B, Hizaoui F, Dargouth M, Gueddiche Z, Kallel G, Balansard G, Boukef K (1996) A clinical trial of a titrated Olea extract in the treatment of essential arterial hypertension. J Pharm Belg 51:69-71

13. Susalit E, Agus N, Effendi I et al (2011) Olive (Olea europaea) leaf extract effective in patients with stage-1 hypertension: comparison with Captopril. Phytomedicine 18:251-258

14. Fonollá J, Díaz-Ropero P, de la Fuente E et al (2010) MS358 One-month consumption of an olive leaf extract enhances cardiovascular status in hypercholesterolemic subjects. Atheroscler Suppl 11:182

15. Filip R, Possemiers S, Heyerick A et al (2015) Twelve-month consumption of a polyphenol extract from olive (Olea europaea) in a double blind, randomized trial increases serum total osteocalcin levels and improves serum lipid profiles in 
postmenopausal women with osteopenia. J Nutr Health Aging 19:77-86. doi:10.1007/s12603-014-0480-x

16. Lockyer S, Corona G, Yaqoob P et al (2015) Secoiridoids delivered as olive leaf extract induce acute improvements in human vascular function and reduction of an inflammatory cytokine: a randomised, double-blind, placebo-controlled, cross-over trial. Br J Nutr 114:75-83

17. Esposito K, Marfella R, Ciotola M et al (2004) Effect of a Mediterranean-style diet on endothelial dysfunction and markers of vascular inflammation in the metabolic syndrome. JAMA J Am Med Assoc 292:1440-1446. doi:10.1001/jama.292.12.1440

18. Fuentes F, López-Miranda J, Sánchez E et al (2001) Mediterranean and low-fat diets improve endothelial function in hypercholesterolemic men. Ann Intern Med 134:1115-1119

19. Ryan M, McInerney D, Owens D et al (2000) Diabetes and the Mediterranean diet: a beneficial effect of oleic acid on insulin sensitivity, adipocyte glucose transport and endothelium-dependent vasoreactivity. QJM 93:85-91. doi:10.1093/qjmed/93.2.85

20. Moreno-Luna R, Muñoz-Hernandez R, Miranda ML et al (2012) Olive oil polyphenols decrease blood pressure and improve endothelial function in young women with mild hypertension. Am J Hypertens 25:1299-1304

21. Ruano J, Lopez-Miranda J, Fuentes F et al (2005) Phenolic content of virgin olive oil improves ischemic reactive hyperemia in hypercholesterolemic patients. J Am Coll Cardiol 46:1864-1868

22. de Bock M, Derraik JG, Brennan CM et al (2013) Olive (Olea europaea L.) leaf polyphenols improve insulin sensitivity in middle-aged overweight men: a randomized, placebo-controlled, crossover trial. PLoS One 8:e57622

23. Gt M (2005) Lowering blood pressure for cardiovascular risk reduction. J Hypertens Suppl 23:S3-S8

24. EFSA (2011) Guidance on the scientific requirements for health claims related to antioxidants, oxidative damage and cardiovascular health. EFSA J 9:2474-2487

25. Laurent S, Boutouyrie P, Asmar R et al (2001) Aortic stiffness is an independent predictor of all-cause and cardiovascular mortality in hypertensive patients. Hypertension 37:1236-1241

26. Tanaka H, Munakata M, Kawano Y et al (2009) Comparison between carotid-femoral and brachial-ankle pulse wave velocity as measures of arterial stiffness. J Hypertens 27:2022-2027

27. Karatzi KPC, Karatzis E, Papaioannou T, Aznaouridis K, Katsichti P, Stamatelopoulos K, Zampelas A, Lekakis J, Mavrikakis M (2005) Red wine acutely induces favorable effects on wave reflections and central pressures in coronary artery disease patients. Am J Hypertens 18:1161-1167

28. Vlachopoulos CAN, Dima I, Aznaouridis K, Andreadou I, Stefanadis C (2006) Acute effect of black and green tea on aortic stiffness and wave reflections. J Am Coll Nutr 25:216-223

29. Yasmin BM (1999) Similarities and differences between augmentation index and pulse wave velocity in the assessment of arterial stiffness. QJM 92:595-600

30. Wilkinson IBMH, Flint L, Cockcroft J, Newby D, Webb D (2000) The influence of heart rate on augmentation index and central arterial pressure in humans. J Physiol 525:263-270

31. Chobanian AV, Bakris GL, Black HR et al (2003) The seventh report of the joint national committee on prevention, detection, evaluation, and treatment of high blood pressure: the JNC 7 report. J Am Med Assoc 289:2560-2571

32. New Zealand Guidelines Group (2009) New Zealand cardiovascular guidelines handbook: a summary resource for primary care practitioners, 2nd edn. New Zealand Guidelines Group, Wellington

33. Cook NR, Cohen J, Hebert PR et al (1995) Implications of small reductions in diastolic blood pressure for primary prevention. Arch Intern Med 155:701-709. doi:10.1001/archi nte.1995.00430070053006
34. Neutel JM (2006) The role of combination therapy in the management of hypertension. Nephrol Dial Transplant 21:14691473. doi:10.1093/ndt/gfk064

35. Rauwald HW, Brehm O, Odenthal KP (1994) Screening of nine vasoactive medicinal plants for their possible calcium antagonistic activity. Strategy of selection and isolation for the active principles of Olea europaea and Peucedanum ostruthium. Phytother Res 8:135-140. doi:10.1002/ptr.2650080303

36. Scheffler A, Rauwald HW, Kampa B et al (2008) Olea europaea leaf extract exerts L-type $\mathrm{Ca}^{2+}$ channel antagonistic effects. J Ethnopharmacol 120:233-240

37. Kang DG, Lee YS, Kim HJ et al (2003) Angiotensin converting enzyme inhibitory phenylpropanoid glycosides from Clerodendron trichotomum. J Ethnopharmacol 89:151-154. doi:10.1016/ S0378-8741(03)00274-5

38. Hansen K, Adsersen A, Christensen SB et al (1996) Isolation of an angiotensin converting enzyme (ACE) inhibitor from Olea europaea and Olea lancea. Phytomedicine 2:319-325

39. Bock M, Thorstensen EB, Derraik JG et al (2013) Human absorption and metabolism of oleuropein and hydroxytyrosol ingested as olive (Olea europaea L.) leaf extract. Mol Nutr Food Res 57:2079-2085

40. Conway J, Johnston J, Coats A et al (1988) The use of ambulatory blood pressure monitoring to improve the accuracy and reduce the numbers of subjects in clinical trials of antihypertensive agents. J Hypertens 6:111-116

41. Ruano J, López-Miranda J, de la Torre R et al (2007) Intake of phenol-rich virgin olive oil improves the postprandial prothrombotic profile in hypercholesterolemic patients. Am J Clin Nutr 86:341-346

42. Perona JS, Cabello-Moruno R, Ruiz-Gutierrez V (2006) The role of virgin olive oil components in the modulation of endothelial function. J Nutr Biochem 17:429-445

43. Carluccio MA, Massaro M, Scoditti E et al (2007) Vasculoprotective potential of olive oil components. Mol Nutr Food Res 51:1225-1234. doi:10.1002/mnfr.200600305

44. Tsimidou MZ, Papoti VT (2010) Bioactive ingredients in olive leaves. In: Preedy VR (ed) Olives and olive oil in health and disease prevention. Elsevier Inc, London, pp 349-356

45. Somova LI, Shode FO, Ramnanan P et al (2003) Antihypertensive, antiatherosclerotic and antioxidant activity of triterpenoids isolated from Olea europaea, subspecies africana leaves. J Ethnopharmacol 84:299-305

46. Gould AL, Rossouw JE, Santanello NC et al (1998) cholesterol reduction yields clinical benefit: impact of statin trials. Circulation 97:946-952. doi:10.1161/01.cir.97.10.946

47. Mihaylova B, Emberson J, Blackwell L et al (2012) The effects of lowering LDL cholesterol with statin therapy in people at low risk of vascular disease: meta-analysis of individual data from 27 randomised trials. Lancet 380:581-590. doi:10.1016/ s0140-6736(12)60367-5

48. Hokanson JE, Austin MA (1996) Plasma triglyceride level is a risk factor for cardiovascular disease independent of highdensity lipoprotein cholesterol level: a metaanalysis of population-based prospective studies. J Cardiovasc Risk 3:213-219. doi:10.1177/174182679600300214

49. Lee J-S, Choi M-S, Jeon S-M et al (2001) Lipid-lowering and antioxidative activities of 3,4-di( $\mathrm{OH})$-cinnamate and 3,4-di(OH)hydrocinnamate in cholesterol-fed rats. Clin Chim Acta 314:221-229

50. Krzeminski R, Gorinstein S, Leontowicz H et al (2003) Effect of different olive oils on bile excretion in rats fed cholesterol-containing and cholesterol-free diets. J Agric Food Chem 51:57745779. doi:10.1021/jf030088a

51. Liu J, Rajendram R, Zhang L (2010) Effects of oleanolic acid and maslinic acid on glucose and lipid metabolism: implications 
for the beneficial effects of olive oil on health. In: Preedy VR (ed) Olives and olive oil in health and disease prevention. Elsevier Inc, London, pp 1423-1429

52. Dibbs Z, Thornby J, White BG et al (1999) Natural variability of circulating levels of cytokines and cytokine receptors in patients with heart failure: implications for clinical trials. J Am Coll Cardiol 33:1935-1942. doi:10.1016/s0735-1097(99)00130-8

53. Rizza L, Munafo S, Serraino A (2012) Compositions for the treatment of hemorrhoids and related diseases. http://www. google.com/patents/US20120183627

54. Impellizzeri D, Esposito E, Mazzon E et al (2011) Oleuropein aglycone, an olive oil compound, ameliorates development of arthritis caused by injection of collagen type II in mice. J Pharmacol Exp Ther 339:859-869

55. Miles EA, Zoubouli P, Calder PC (2005) Differential anti-inflammatory effects of phenolic compounds from extra virgin olive oil identified in human whole blood cultures. Nutrition 21:389-394

56. Boekholdt SM, Peters RJ, Hack CE et al (2004) IL-8 plasma concentrations and the risk of future coronary artery disease in apparently healthy men and women the EPIC-norfolk prospective population study. Arterioscler Thromb Vasc Biol 24:1503-1508
57. Shin WS, Szuba A, Rockson SG (2002) The role of chemokines in human cardiovascular pathology: enhanced biological insights. Atherosclerosis 160:91-102

58. D’Agostino RB Sr, Pencina MJ, Massaro JM et al (2013) Cardiovascular disease risk assessment: insights from Framingham. Glob Heart 8:11-23. doi:10.1016/j.gheart.2013.01.001

59. Komaki EYS, Maru I, Kinoshita M, Kakehi K, Ohta Y, Tsukada $Y$ (2003) Identification of anti- $\alpha$-amylase components from olive leaf extracts. Food Sci Technol Res 9:35-39

60. Fito M, Cladellas M, de la Torre R et al (2008) Anti-inflammatory effect of virgin olive oil in stable coronary disease patients: a randomized, crossover, controlled trial. Eur J Clin Nutr 62:570-574. doi:10.1038/sj.ejen.1602724

61. Committee Guidelines (2003) European Society of Hypertension-European Society of Cardiology guidelines for the management of arterial hypertension. J Hypertens 21:1011-1053

62. National Institute of Health and Care Excellence (2014) Lipid modification: cardiovascular risk assessment and the modification of blood lipids for the primary and secondary prevention of cardiovascular disease. http://www.nice.org.uk/guidance/CG181/ chapter/1-Recommendations\#lifestyle-modifications-for-the-primary-and-secondary-prevention-of-cvd 